\title{
BMJ
}

\section{Effect of 20 mph traffic speed zones on road injuries in London, 1986-2006: controlled interrupted time series analysis}

\author{
Chris Grundy, lecturer in geographical information systems, ${ }^{1}$ Rebecca Steinbach, research fellow, ${ }^{1}$ Phil \\ Edwards, senior lecturer in statistics, ${ }^{2}$ Judith Green, reader in sociology of health, ${ }^{1}$ Ben Armstrong, professor of \\ epidemiological statistics, ${ }^{1}$ Paul Wilkinson, reader in environmental epidemiology ${ }^{1}$
}

${ }^{1}$ Department of Public Health and Policy, London School of Hygiene and Tropical Medicine, London WC1E 7HT

${ }^{2}$ Department of Epidemiology and Population Health, London School of Hygiene and Tropical Medicine, London

Correspondence to: C Grundy chris.grundy@lshtm.ac.uk

Cite this as: $B M J$ 2009;339:b4469 doi:10.1136/bmi.b4469

\section{ABSTRACT}

Objective To quantify the effect of the introduction of 20 $\mathrm{mph}$ (32 km an hour) traffic speed zones on road collisions, injuries, and fatalities in London.

Design Observational study based on analysis of geographically coded police data on road casualties, 1986-2006. Analyses were made of longitudinal changes in counts of road injuries within each of 119029 road segments with at least one casualty with conditional fixed effects Poisson models. Estimates of the effect of introducing $20 \mathrm{mph}$ zones on casualties within those zones and in adjacent areas were adjusted for the underlying downward trend in traffic casualties. Setting London.

Main outcome measures All casualties from road collisions; those killed and seriously injured (KSI). Results The introduction of $20 \mathrm{mph}$ zones was associated with a $41.9 \%$ (95\% confidence interval $36.0 \%$ to $47.8 \%$ ) reduction in road casualties, after adjustment for underlying time trends. The percentage reduction was greatest in younger children and greater for the category of killed or seriously injured casualties than for minor injuries. There was no evidence of casualty migration to areas adjacent to $20 \mathrm{mph}$ zones, where casualties also fell slightly by an average of $8.0 \%$ ( $4.4 \%$ to $11.5 \%)$. Conclusions $20 \mathrm{mph}$ zones are effective measures for reducing road injuries and deaths.

\section{INTRODUCTION}

Road injuries are among the leading causes of loss of life and disability worldwide, ${ }^{1}$ and they are projected to make an increasingly important contribution to public health burdens over the coming decades, ${ }^{2}$ especially in low and middle income settings. ${ }^{3}$ Internationally, there is debate around how the development of transport infrastructure needed to meet the United Nations millennium development goals can be achieved without adding to the burden of injury that is currently disproportionately borne by poor pedestrians, particularly children and young adults. ${ }^{4-6}$ The United Kingdom has a comparatively good road injury record, with injury rates among the lowest in Europe. Nonetheless, in 2006 there were 2858 deaths and 26066 serious injuries on roads in England and Wales, ${ }^{7}$ and reduction in these numbers remains a major aim of public policy. ${ }^{8}$

There is good evidence internationally for the effectiveness of reducing the speed and volume of traffic for reducing injury rates. ${ }^{9-11}$ One strategy for reducing speeds in urban areas is the use of road engineering interventions such as vertical deflections (humps), chicanes, and other physical alterations to prevent motorised traffic travelling at more than 20 miles an hour (32 km an hour). Zones in which traffic is limited to $20 \mathrm{mph}$ are a type of area-wide traffic calming that uses road engineering measures to physically slow traffic. Over the past 15 years or so, $20 \mathrm{mph}$ zones have been established in London and many other areas of the UK.

Depending on the local environment, a range of vertical and horizontal deflections, as well as other measures, are implemented. Typically, zones are marked by terminal signs at the entrance and exit of the zone, and traffic calming measures (such as speed humps, chicanes, and raised junctions) are placed every 100 metres. The designs of $20 \mathrm{mph}$ zones vary, but all are designed to ensure slower traffic speeds using self enforcing engineering and design features that comply with Traffic Signs and General Directions 2002 Regulations. When proposing $20 \mathrm{mph}$ zones, local authorities are legally required to consult with relevant stakeholders such as the emergency services, local residents, and organisations representing road users. Limited evidence suggests that the self enforcing $20 \mathrm{mph}$ zones are effective in reducing traffic speeds to an average of $17 \mathrm{mph}$, an average reduction of $9 \mathrm{mph} .^{12}$ The benefit of these $20 \mathrm{mph}$ zones in reducing road casualties, however, has not been conclusively established.

With relatively robust data on road traffic injuries, London provides a good case study for evaluating the effect of $20 \mathrm{mph}$ zones. We carried out a detailed assessment of such schemes, based on analysis of data on 20 years of geographically referenced road casualties in London. 


\section{METHODS}

Analysis was based on Police STATS19 data, 19862006, which record the date, location, and number and type of casualties for all road collisions related to injury (damage only collisions are excluded). STATS19 data record the severity of injury to each casualty as slight, serious, or fatal. A casualty is defined as serious if the person is detained in hospital as an inpatient or has any of the following injuries (whether or not the person is detained in hospital): fractures, concussion, internal injuries, crushing, non-friction burns, severe cuts and lacerations, or severe general shock requiring medical treatment. A casualty is classified as fatal if the person dies within 30 days of the collision. By using a geographical information system (GIS), we linked these casualty data to a detailed road segment database that included the characteristics of all classified and unclassified roads in London. For each financial year (April to March), we classified each segment of road between junctions according to the type of road and whether or not it was in a $20 \mathrm{mph}$ zone or adjacent to a $20 \mathrm{mph}$ zone. Each segment was further classified by the super output area in which it was located. A super output area is a small geographical area, defined for the reporting of census statistics, which on average contains a population of around 1500. Where a super output area boundary or 20 $\mathrm{mph}$ zone cut across a single road segment, that segment was divided into smaller segments as necessary. The database for London contained 298644 separate road segments (table 1).

Each segment was further classified by the date engineering works started (decision date) on the $20 \mathrm{mph}$ zone (where relevant) and the date it started to be enforced, which might have been several years after

Table 1 |Characteristics of road segments by area type. Figures are numbers (percentages)

\begin{tabular}{|c|c|c|c|}
\hline & $20 \mathrm{mph}$ zones & Adjacent areas & Other roads \\
\hline \multicolumn{4}{|c|}{ Length $(\mathrm{km})$ of roads (column \%) by road type: } \\
\hline Motorways & $0(0)$ & $3(0)$ & $130(1)$ \\
\hline A roads & $14(1)$ & $584(26)$ & $1732(12)$ \\
\hline$B$ roads & $39(2)$ & $111(5)$ & $385(3)$ \\
\hline Minor & $1739(86)$ & $1307(59)$ & $9529(68)$ \\
\hline Other & $214(11)$ & $211(10)$ & $2136(15)$ \\
\hline Total & $2006(100)$ & $2216(100)$ & $13913(100)$ \\
\hline Road length $(\mathrm{km})$ in inner London & $1263(63)$ & $1109(50)$ & $2780(20)$ \\
\hline \multicolumn{4}{|l|}{ No of injuries, financial year 2006: } \\
\hline Minor & $523(91)$ & $5865(87)$ & $20836(87)$ \\
\hline Serious & $52(9)$ & $782(12)$ & $2920(12)$ \\
\hline Deaths & $1(0)$ & $41(1)$ & $182(1)$ \\
\hline \multicolumn{4}{|l|}{ No of injuries, 1987-2006: } \\
\hline Minor & $39766(85)$ & $204262(85)$ & $520167(84)$ \\
\hline Serious & $7002(15)$ & $33946(14)$ & $89433(15)$ \\
\hline Deaths & $220(0)$ & $1642(1)$ & $4366(1)$ \\
\hline \multicolumn{4}{|l|}{ No of injuries after implementation: } \\
\hline Minor & 1704 (89) & $22130(87)$ & NA \\
\hline Serious & $210(11)$ & 3015 (12) & NA \\
\hline Deaths & $8(0)$ & $182(1)$ & NA \\
\hline
\end{tabular}

$\mathrm{NA}=$ not applicable.

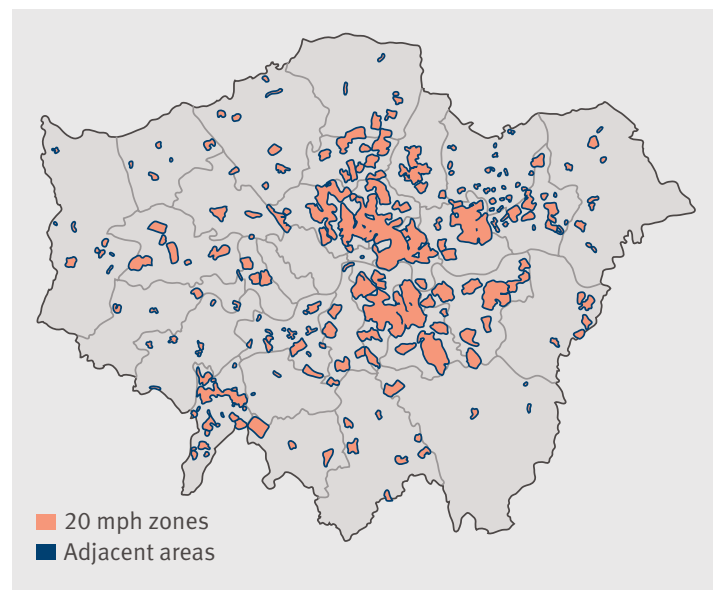

Fig 1 | Location of 20 mph speed zones in London (1991-2007), based on census boundaries, which are OS copyright

the date of decision. Thus, using these dates, each road segment was classified as pre-intervention, under construction, or post-implementation. The intervention status was assumed to change only at the beginning of each financial year, so that a change from "under construction" to "post-implementation" status, for example, occurred on 1 April after the implementation date. We had information on decision and implementation dates for 385 of the 399 zones introduced in London from 1991 to 2007.

The geographical information system was also used to generate adjacent areas around $20 \mathrm{mph}$ zones, which included all roads connecting junctions within 150 metres of the perimeter of the $20 \mathrm{mph}$ zone. In this way we defined three types of roads: those that were within or would become part of a $20 \mathrm{mph}$ zone, those that were part of an area adjacent to a $20 \mathrm{mph}$ zone, and all other roads (fig 1).

Linkage of the STATS19 data to road segments was done by a combination of spatial overlay and the use of text descriptor of road location. In brief, the algorithm assigned a road injury to the nearest road segment of the type indicated in the STATS19 report. Road injuries occurring more than 50 metres away from a road segment of the appropriate type were assigned to the nearest road segment, regardless of type. We excluded from the analysis road injuries occurring more than 100 metres from any road segment (fig 2).

From the combined dataset, we generated counts of casualties and collisions for each road segment and year. The road segments enable stratification of the results by intervention status, adjacency status, and borough. Road casualty data provided the basis of stratification by age group $(0-5,6-11,12-15, \geq 16)$ and sex.

\section{Statistical methods}

Our primary focus was to characterise the influence of the $20 \mathrm{mph}$ zones on casualties and collisions within segments after allowing for underlying trends over time. It is difficult to define appropriate population denominators for rate estimation on individual road segments and, as road user data were not collected, 


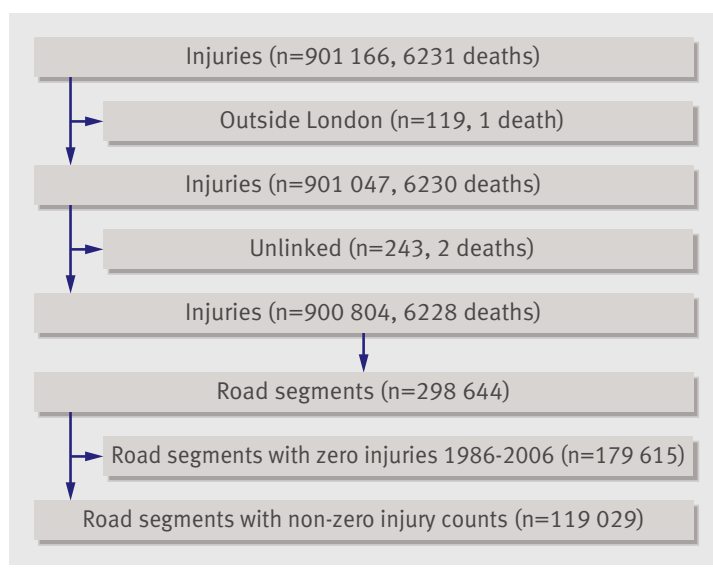

Fig 2 | Number of injuries (deaths) and road segments used in analysis

analyses were based on the patterns of change in annual counts within each road segment. Therefore for optimal control of confounding, the analysis instead compares change in injury counts within the $20 \mathrm{mph}$ zone before and after introduction of the zone relative to trends seen on other roads. The estimated effect is therefore specific to $20 \mathrm{mph}$ zones compared with other roads. Technically, to implement this we used conditional fixed effects Poisson models using Stata's xtpoisson command. The number of casualties or collisions, $\mathrm{y}_{\mathrm{s}, \mathrm{t}}$ in road segment $\mathrm{s}$ in year $\mathrm{t}$ is defined as follows:

$\mathrm{Y}_{\mathrm{s}, \mathrm{t}} \sim \operatorname{Poisson}\left(\mu_{\mathrm{s}, \mathrm{t}}\right)$

$\log \left(\mu_{\mathrm{s}, \mathrm{t}}\right)=\alpha_{\mathrm{s}}+\mathrm{S}\left(\mathrm{t}, \mathrm{z}_{\mathrm{s}}\right)+\beta \mathrm{x}_{\mathrm{s} . \mathrm{t}}$

where $\alpha_{\mathrm{s}}$ is the road segment effect, $\mathrm{S}\left(\mathrm{t}, \mathrm{z}_{\mathrm{s}}\right)$ is a function of year to allow for London-wide trends in casualties or collisions, dependent on road segment characteristics $\mathrm{z}_{\mathrm{s}}, \mathrm{x}_{\mathrm{s} . \mathrm{t}}$ is a vector of indicator $(0,1)$ variables identifying road segments in $20 \mathrm{mph}$ zones and (separately) adjacent areas, after the zone had been put into operation, and $B$ is a vector of coefficients representing the effect of $20 \mathrm{mph}$ zones and adjacent areas on casualties.

The $\alpha_{s}$ nuisance parameters are "conditioned out" in the conditional fixed effects Poisson model, allowing models to be based on annual counts of casualties and collisions within each road segment. For transparency, we fitted the underlying trends in casualties and collisions $\left(\left(\mathrm{S}\left(\mathrm{t}, \mathrm{z}_{\mathrm{s}}\right)\right)\right.$ with linear terms. The results for the 20 $\mathrm{mph}$ zone effect might be interpreted as the before and after change in the number of casualties within road segments within $20 \mathrm{mph}$ zones adjusted for the (broadly downward) trends in casualties on other roads. Robust standard errors were obtained with jackknife procedures, clustering on borough $(\mathrm{n}=32)$. Analyses were stratified by age group and sex.

We carried out sensitivity analyses to examine several model assumptions. We used other smooth functions of time and terms for individual years to control for the underlying trend in casualties and collisions over time. We restricted analyses to minor roads only (B roads, minor roads, and other roads). We restricted analyses to the period 2000-6 to examine the effect of the more recently introduced $20 \mathrm{mph}$ zones. We also carried out analyses to examine the effect of potential influence of regression to the mean arising from the fact that high injury numbers might have been a factor in the decision to implement a $20 \mathrm{mph}$ zone in some areas. For this, we repeated the analyses excluding data for periods of three, four, and five years before the implementation of each $20 \mathrm{mph}$ zone. Finally, we examined whether the effect of $20 \mathrm{mph}$ zones is modified by location (inner versus outer London).

\section{RESULTS}

Over the period 1987-2006, there has been a more or less steady decline in the number of road casualties in London, with similar patterns for all casualties and for those killed and seriously injured. The decline seems marginally steeper in the most recent years. The total length of roads inside $20 \mathrm{mph}$ zones has increased rapidly since the mid-1990s, and the casualty numbers on those road segments have fallen steeply in recent years.

\section{Effect of $20 \mathrm{mph}$ zones}

Table 2 summarises the effect of the $20 \mathrm{mph}$ zones on casualties and collisions. The models used to derive these estimates allow for the (generally) downward trend over time in the annual number of casualties and collisions in London.

The introduction of the $20 \mathrm{mph}$ zones was associated with a reduction in casualties and collisions of around $40 \%$. Casualties as a whole were reduced by $41.9 \%$ ( $95 \%$ confidence interval $36.0 \%$ to $47.8 \%$ ), with slightly larger point estimates for the reductions in all casualties in children aged 0-15 and in the numbers killed or seriously injured. The numbers of killed or seriously injured children were reduced by half $(50.2 \%, 37.2 \%$ to $63.2 \%$ ). The point estimate of the reduction in number of people killed was slightly smaller at $35.1 \%$, $-1.9 \%$ to $72.0 \%$ ).

Injuries to pedestrians were reduced by a little under a third, but again with higher point estimates in children aged 0-15 (similar for boys and girls), and in the number of killed or seriously injured children. The observed reductions were largest for the youngest children (0-5 and 6-11). There was a smaller reduction in casualties among cyclists, $16.9 \%$ (4.8\% to $29.0 \%$ ) than for any of the other major groups of outcomes. The reduction of casualties among cyclists was also greater in children aged 0-15 and in those killed or seriously injured.

Casualties involving riders of powered two wheeled vehicles declined by a little under a third, and those of car occupants fell by half. In both cases, the estimates for the effect on the numbers killed or seriously injured were slightly greater than for casualties overall.

Data on casualties in areas adjacent to $20 \mathrm{mph}$ zones also showed evidence of small (generally single figure) percentage reductions after implementation of the zones. The only point estimates of relative increase were for deaths overall, pedestrians killed or seriously injured, child pedestrians killed or seriously injured, 
Table 2 | Effect (percentage reduction) of introducing $20 \mathrm{mph}$ zones on casualties and collisions in $20 \mathrm{mph}$ zones and in adjacent areas, and annual average decline in casualties and collisions on other roads, 1986-2006

\begin{tabular}{|c|c|c|c|}
\hline & \multicolumn{2}{|c|}{$\begin{array}{l}\text { Per cent reduction }(95 \% \mathrm{Cl}) \text { after introduction } \\
\text { of } 20 \mathrm{mph} \text { zones }\end{array}$} & \multirow{2}{*}{$\begin{array}{l}\text { Annual average \% decline in } \\
\text { casualties and collisions } \\
\text { (underlying trend) }\end{array}$} \\
\hline & In $20 \mathrm{mph}$ zones & Adjacent areas & \\
\hline \multicolumn{4}{|l|}{ Casualties: } \\
\hline All casualties & 41.9 (36.0 to 47.8$)$ & $8.0(4.4$ to 11.5$)$ & 1.7 (1.5 to 1.9$)$ \\
\hline All casualties ( $0-15$ years) & 48.5 (41.9 to 55.0$)$ & 9.7 (4.5 to 14.9$)$ & 3.4 (3.1 to 3.7 ) \\
\hline $\mathrm{KSI}$ * & 46.3 (38.6 to 54.1$)$ & $7.9(2.2$ to 13.5$)$ & $3.8(3.4$ to 4.1$)$ \\
\hline $\mathrm{KSI}{ }^{*}(0-15$ years $)$ & $50.2(37.2$ to 63.2$)$ & $5.4(-8.1$ to 18.8$)$ & $5.2(4.7$ to 5.8$)$ \\
\hline Killed & $35.1(-1.9$ to 72.0$)$ & $-21.1(-52.3$ to 10.2$)$ & $4.0(3.4$ to 4.6$)$ \\
\hline \multicolumn{4}{|l|}{ Pedestrian casualties: } \\
\hline All pedestrians & $32.4(27.1$ to 37.7$)$ & $4.3(-1.0$ to 9.6$)$ & 3.4 (3.2 to 3.6$)$ \\
\hline $0-15$ years & $46.2(36.8$ to 55.5$)$ & $5.3(-1.3$ to 11.9$)$ & 3.9 (3.6 to 4.3$)$ \\
\hline $\mathrm{KSI}{ }^{*}$ & $34.8(22.2$ to 47.5$)$ & $-2.1(-13.6$ to 9.3$)$ & $5.5(5.2$ to 5.9$)$ \\
\hline $\mathrm{KSI}^{\star}, 0-15$ years & $43.9(26.6$ to 61.3$)$ & $-4.5(-23.0$ to 14.0$)$ & $6.1(5.5$ to 6.7$)$ \\
\hline Male, $0-15$ years & 45.5 (35.6 to 55.3$)$ & $8.2(0.7$ to 15.7$)$ & 4.1 (3.7 to 4.5$)$ \\
\hline Female, $0-15$ years & $47.2(33.1$ to 61.2$)$ & $0.9(-10.0$ to 11.7$)$ & 3.7 (3.4 to 4.0$)$ \\
\hline $0-5$ years & $47.0(28.7$ to 65.2$)$ & $9.9(-11.8$ to 31.6$)$ & $4.0(3.5$ to 4.5$)$ \\
\hline $6-11$ years & 50.8 (40.9 to 60.8) & $3.7(-8.5$ to 16.0$)$ & $4.8(4.3$ to 5.2$)$ \\
\hline $12-15$ years & $26.3(5.9$ to 46.7$)$ & $6.3(-4.1$ to 16.7$)$ & $2.8(2.5$ to 3.1$)$ \\
\hline \multicolumn{4}{|l|}{ Cyclists: } \\
\hline All cyclists & 16.9 (4.8 to 29.0$)$ & $4.6(-2.5$ to 11.7$)$ & 2.0 (1.3 to 2.7$)$ \\
\hline $\mathrm{KSI}{ }^{\star}$ & 37.6 (14.4 to 60.9) & $-2.1(-19.5$ to 15.2$)$ & $3.1(2.2$ to 4.0$)$ \\
\hline $0-15$ years & 27.7 (6.3 to 49.1$)$ & $6.2(-10.8$ to 23.2$)$ & $4.7(4.1$ to 5.3$)$ \\
\hline$\geq 16$ years & $7.3(-10.3$ to 24.9$)$ & $7.2(-0.11$ to 4.6$)$ & $1.4(0.7$ to 2.0$)$ \\
\hline \multicolumn{4}{|l|}{ Powered two wheeled vehicle riders: } \\
\hline All casualties & $32.6(21.7$ to 43.4$)$ & $9.4(2.7$ to 16.1$)$ & $0.6(0.2$ to 1.0$)$ \\
\hline $\mathrm{KSI}{ }^{*}$ & 39.1 (19.0 to 59.1) & $3.2(-10.2$ to 16.6$)$ & 2.4 (1.9 to 3.0$)$ \\
\hline \multicolumn{4}{|l|}{ Car occupant: } \\
\hline All car occupants & $52.5(42.5$ to 62.4$)$ & 11.5 (6.4 to 16.5$)$ & 1.1 (0.8 to 1.5$)$ \\
\hline $\mathrm{KSI}{ }^{*}$ & 61.8 (52.0 to 71.7$)$ & 24.4 (15.7 to 33.0) & $2.8(2.2$ to 3.5$)$ \\
\hline \multicolumn{4}{|l|}{ Collisions: } \\
\hline All collisions & 37.5 (31.6 to 43.4$)$ & $7.4(3.8$ to 11.0$)$ & 1.8 (1.6 to 2.0$)$ \\
\hline $\mathrm{KSI}{ }^{*}$ & $44.2(36.6$ to 51.7$)$ & $7.5(2.0$ to 13.1$)$ & $3.8(3.4$ to 4.1$)$ \\
\hline Involving $\geq 1$ pedestrian & 30.1 (23.5 to 36.5$)$ & $4.1(-1.3$ to 9.4$)$ & $3.4(3.2$ to 3.6$)$ \\
\hline Involving $\geq 1$ cyclist & $16.6(5.6$ to 22.7$)$ & $4.4(-2.7$ to 11.5$)$ & $2.0(1.3$ to 2.7$)$ \\
\hline Involving $\geq 1$ powered two wheeled vehicle riders & 31.7 (21.2 to 42.3$)$ & $9.8(2.8$ to 16.8$)$ & $0.6(0.1$ to 1.0$)$ \\
\hline
\end{tabular}

and cyclists killed or seriously injured, but for these outcomes the results were also consistent with no effect or reduced risk. This suggests that casualties inside $20 \mathrm{mph}$ zones are not being displaced to nearby roads.

The general trend in casualties and collisions over time in London, an annual decline of $1.7 \%$, was equivalent to a $15.8 \%$ reduction over 10 years or a $29.0 \%$ reduction over 20 years. Thus, in broad terms, the additional effect of the $20 \mathrm{mph}$ zones was that of a step reduction in casualties and collisions by an amount that has taken over 20 years to achieve on roads without $20 \mathrm{mph}$ zones.

\section{Sensitivity analyses}

Alternative methods of control for long term trends in casualties and collisions had only a minor effect on the point estimates and confidence intervals for the 20 mph zone effect on each of the major outcomes. For example, fitting indicators for individual years yielded an estimate of reduction of $36.5 \%(29.5 \%$ to $43.5 \%)$ in all casualties within $20 \mathrm{mph}$ zones and $42.0 \%$ (33.4\% to $50.6 \%$ ) for killed or seriously injured casualties. Exclusion of motorways and A roads from the analysis made little difference to the pattern of results. We found no evidence that the effect of $20 \mathrm{mph}$ zones differed between inner and outer London, suggesting that the effect of the intervention is not modified by location.

When we restricted analyses to 2000-6, the period with the lowest annual numbers of casualties, the results for the effects of $20 \mathrm{mph}$ zones showed slightly smaller percentage reductions of $22.7 \%(15.3 \%$ to $30.1 \%)$ for all casualties, $28.4 \%(17.8 \%$ to $39.0 \%)$ for killed or seriously injured, and $21.6 \%$ (12.9\% to $30.4 \%$ ) for all pedestrian injuries. In the case of cyclists, the point estimate suggests almost no effect $(-1.3 \%$, $-22.3 \%$ to $19.8 \%)$.

Removal of data for three, four, and five years before the introduction of the zones had little effect on the 


\section{WHAT IS ALREADY KNOWN ON THIS TOPIC}

Road injuries are among the leading causes of mortality and disability worldwide

There is evidence that reducing the speed and volume of traffic can reduce rates of road traffic injury

\section{WHAT THIS STUDY ADDS}

$20 \mathrm{mph}$ zones are effective measures for reducing road injuries with no evidence of casualty migration to nearby roads compared with other road types. National evidence suggests that the rate of under-reporting overall has not substantially changed over time. ${ }^{14}$

We could not take into account the potential impact of other road safety initiatives, such as road safety cameras. If they were introduced more often in $20 \mathrm{mph}$ zones and adjacent areas than elsewhere, it is possible some degree of the apparent $20 \mathrm{mph}$ zone effect is attributable to these other measures. But it seems unlikely that such "confounding" could account for the greater part of the substantial effects observed on casualties within the $20 \mathrm{mph}$ zones compared with other roads.

We were able to link more than $99 \%$ of casualties to road segments and assign a date specific intervention status to road segments in $96 \%$ of $20 \mathrm{mph}$ zones in London. The results also seem fairly robust to the various forms of sensitivity analysis we performed. In particular, the results based on excluding data for up to five years before the introduction of $20 \mathrm{mph}$ zones suggest no significant bias from regression to the mean (a theoretical concern because high casualty numbers might form part of the rationale for introducing $20 \mathrm{mph}$ zones).$^{15}$ Moreover, the fact that casualty numbers also fell slightly on roads adjacent to $20 \mathrm{mph}$ zones argues against diversion of casualty risk. The results were also not materially affected by using model specifications that compared the change in road casualties within 20 mph zones with that on other minor roads (which are similar in type to the roads within $20 \mathrm{mph}$ zones).

The pattern of findings lends some support to the interpretation that $20 \mathrm{mph}$ zones reduce the severity of injuries more than the frequency of collision, which might be explained by slower motor vehicle speeds. It is gratifying that large reductions were observed in the number of killed and seriously injured casualties, especially in children. A somewhat counterintuitive observation is the apparently large reduction in injuries to car occupants. It is important to remember, however, that all changes are expressed in relative terms, and it is quite possible that a relatively large reduction in casualties in car occupants might occur with slower vehicle speeds and perhaps some diversion of traffic away from previously used "rat runs," even though casualties in car occupants are relatively few in number.

As most collisions occur on roads that, in the UK, are inappropriate for implementation of $20 \mathrm{mph}$ zones (such as A roads), further reduction in casualties from implementing such zones might be limited in settings such as London, where a large proportion of residential areas have already been traffic calmed. Future gains in road safety might be more likely from interventions that also address the risks of major roads.

What we cannot answer from this analysis is how 20 mph zones compare with the effect of other possible forms of traffic control systems, including such innovative ideas as redesigning road layouts to make the space more shared between pedestrians, cyclists, and motor vehicles. Further research is also needed on the impact of traffic calming in other settings in which the background decline in injury rates might be less dramatic, 
particularly in low and middle income settings, where $85 \%$ of road traffic related injuries occur ${ }^{3}$ and where there has been little evaluation of the impact of traffic calming schemes. ${ }^{16}$

The STATS19 and 20 mph zone data were supplied by Peter Sadler at the London Road Safety Unit. The road network used was Ordnance Survey Integrated Transport Network layer supplied by Transport for London under licence and is copyright Ordnance Survey. 2001 census data were supplied with the support of Economic and Social Research Council and are Crown Copyright. Boundaries are Crown and Ordnance Survey copyright. We are grateful to referees for comments on earlier versions of this paper. We thank John Cairns for his contribution to the design of the study.

Contributors: $\mathrm{CG}, \mathrm{RS}, \mathrm{PE}, \mathrm{BA}$, and PW all contributed to the design of the study, analysis of the data, and interpretation of results. JG contributed to the design of the study and interpretation of the results. All authors contributed to the writing of the manuscript. CG is guarantor. Funding: This study was funded by Transport for London (contract No TfL2218). The views expressed in the publication are those of the authors and not necessarily those of Transport for London.

Competing interests: None declared.

Ethical approval: Not required.

Data sharing: No additional data available.

1 Lopez A, Mathers C, Ezzati M, Jamison D, Murray C. Global and regional burden of disease and risk factors, 2001: systematic analysis of population health data. Lancet 2006;367:1747-57.

2 Mathers CD, Loncar D. Projections of global mortality and burden of disease from 2002 to 2030. PLoS Med 2006;3:e442.

3 Hyder AA, Peden M. Inequality and road-traffic injuries: call for action. Lancet 2003;362:2034-5.
4 Cook CC, Duncan T, Jitsuchon S, Sharma A, Guobao W. Assessing the impact of transport and energy infrastructure on poverty reduction. Asian Development Bank, 2005.

5 Hyder AA, Ghaffar A. The millennium development goals and road traffic injuries: exploring the linkages in South Asia. J Coll Physicians Surg Pak 2004;14:742-5.

6 Bannister $D$, Wright $L$. The role of transport in supporting subnational development. Department for International Development, 2005.

7 Department for Transport. Road casualties Great Britain 2006. Stationery Office, 2007.

8 Department for Transport. Tomorrow's roads: safer for everyone. Department for Transport, 2000.

9 Aarts L, van Schagen I. Driving speed and the risk of road crashes: review. Accid Anal Prev 2006;38:215-24.

10 Bunn F, Collier T, Frost C, Ker K, Steinbach R, Roberts I, et al. Areawide traffic calming for preventing traffic related injuries. Cochrane Database Syst Rev 2009;(4):CD003110.

11 Elvik R. Area-wide urban traffic calming schemes: a meta-analysis of safety effects. Accid Anal Prev 2001;33:327-36.

12 Webster D, Layfield R. Review of $20 \mathrm{mph}$ zones in London boroughs. Transport for London, 2003 (project report PPR243).

13 Grundy C, Steinbach R, Edwards P, Wilkinson P, Green J. 20 mph zones and road safety in London: a report to the London Road Safety Unit. London School of Hygiene and Tropical Medicine, 2008

14 Ward H, Lyons R, Thoreau R. Under-reporting of road casualtiesphase 1. Department for Transport, 2006 (Road safety research report No 69).

15 Persaud B, Lyon C. Empirical Bayes before-after safety studies: lessons learned from two decades of experience and future directions. Accid Anal Prev 2007;39:546-55.

16 Bunn F, Collier T, Frost C, Ker K, Roberts I, Wentz R. Traffic calming for the prevention of road traffic injuries: systematic review and metaanalysis. Inj Prev 2003;9:200-4.

Accepted: 14 September 2009 